\title{
Development of an Electronic Incubator for Hen Eggs using a Tire
}

\author{
Joel Flores ${ }^{1}$, Gerardo Suárez ${ }^{2}$ \\ Professor, Communications and Electronic Engineering Department (ICE), ESIME-ZAC, IPN, Mexico City, Mexico ${ }^{1-2}$
}

\begin{abstract}
Poultry are distributed almost all over the world. In western countries the current trend is the specialization of production in poultry farms, some producers are responsible for incubating eggs, others for the production of eggs for consumption and still others for raising chickens for the meat market, therefore this document focuses on the development of an electronic incubator whose control system has the function of regulating the heat, humidity and movement of chicken eggs; kept the eggs in optimum conditions for the development of the embryo.
\end{abstract}

Keywords: Electronic incubator, Incubation of chicken eggs, Temperature and humidity control, Electronic control.

\section{INTRODUCTION}

The hen after laying its eggs does not always enter its cluck state and there is no way for the hen to enter this physiological state; so the poultry farmer needs to wait for the right moment to be able to naturally incubate the eggs, which causes periods of abundance and shortages of chickens. Sometimes some poultry farmers have to invest in a hen house with special conditions to protect the hen and the eggs from overcrowding and possible damage to the eggs, this increases the cost of natural incubation. When hens are in their brood state, it stop producing eggs [1].

The poultry farmer should choose hens that retain their maternal instincts for natural incubation, and that are a good size to cover the eggs. A large breed hen such as the Cobb can hatch up to a maximum of 12 eggs, while small breeds can only hatch up to 7 eggs [2].

Because the production of this type of birds is affected by different factors such as not being able to enter cluck, the rupture of the eggs due to overcrowding, rotten eggs due to time or bad conditions of humidity and heat, etc., it is necessary that some of these factors are reduced. For this reason, artificial incubation solves these factors by keeping the eggs in optimal conditions for the development of the hen embryo [3], [4].

\section{DESCRIPTION}

For the development of this prototype, 6 stages were proposed, 1) the stage corresponding to the chassis: it allows a suitable environment for embryonic development, 2) the registration stage: it includes two sensors to measure the variables temperature and humidity, 3) the actuators stage: allows the control of the mentioned variables and the movement of the eggs, 4) the control stage: the sensors and actuators are operated by means of a microcontroller, in addition to containing a second microcontroller that performs the movement of the eggs from time to time, 5) the display stage: it allows the reading of the temperature and humidity inside the incubator and 6) the power stage: it consists of two types of sources: DC power supply and AC power supply. The block diagram of the incubator prototype is shown in Fig. 1 .

The control parameters that are proposed for the electronic incubator are: the incubation temperature and humidity, the temperature should be between $37^{\circ} \mathrm{C}$ and $38^{\circ} \mathrm{C}$, and the ideal is between $37.5^{\circ} \mathrm{C}$ to $37.8^{\circ} \mathrm{C}$ for 19 days corresponding to the incubation period. The days 20 and 21 correspond to the period of the hatchery, these days the temperature decreases between $36.1^{\circ} \mathrm{C}$ and $37.2^{\circ} \mathrm{C}$. In an incubator, the temperature must remain constant, since it determines the metabolic rate of the embryo and therefore its development speed. During incubation, water vapor is lost through the pores of the shell. The speed with which this moisture is lost depends on the number and size of the pores (the gas conductivity of the shell) and the humidity of the air around the egg. For best hatchability, an egg should lose $12 \%$ of its weight by maximum day 18 of incubation due to loss of water. The relative humidity during the 19 days of the incubation process should be between $55 \%$ and $62 \%$. In the days 20 and 21 of the hatchery period, the relative humidity gradually increases between $65 \%$ and $70 \%$ [2] and [5]. The eggs must be turned during the incubation process. This prevents the embryo from sticking to the shell membranes, particularly in the first week of incubation and helps the development of the embryo's membranes. 


\section{International Journal of Advanced Research in Computer and Communication Engineering}

Vol. 9, Issue 10, October 2020

\section{DOI 10.17148/IJARCCE.2020.91016}

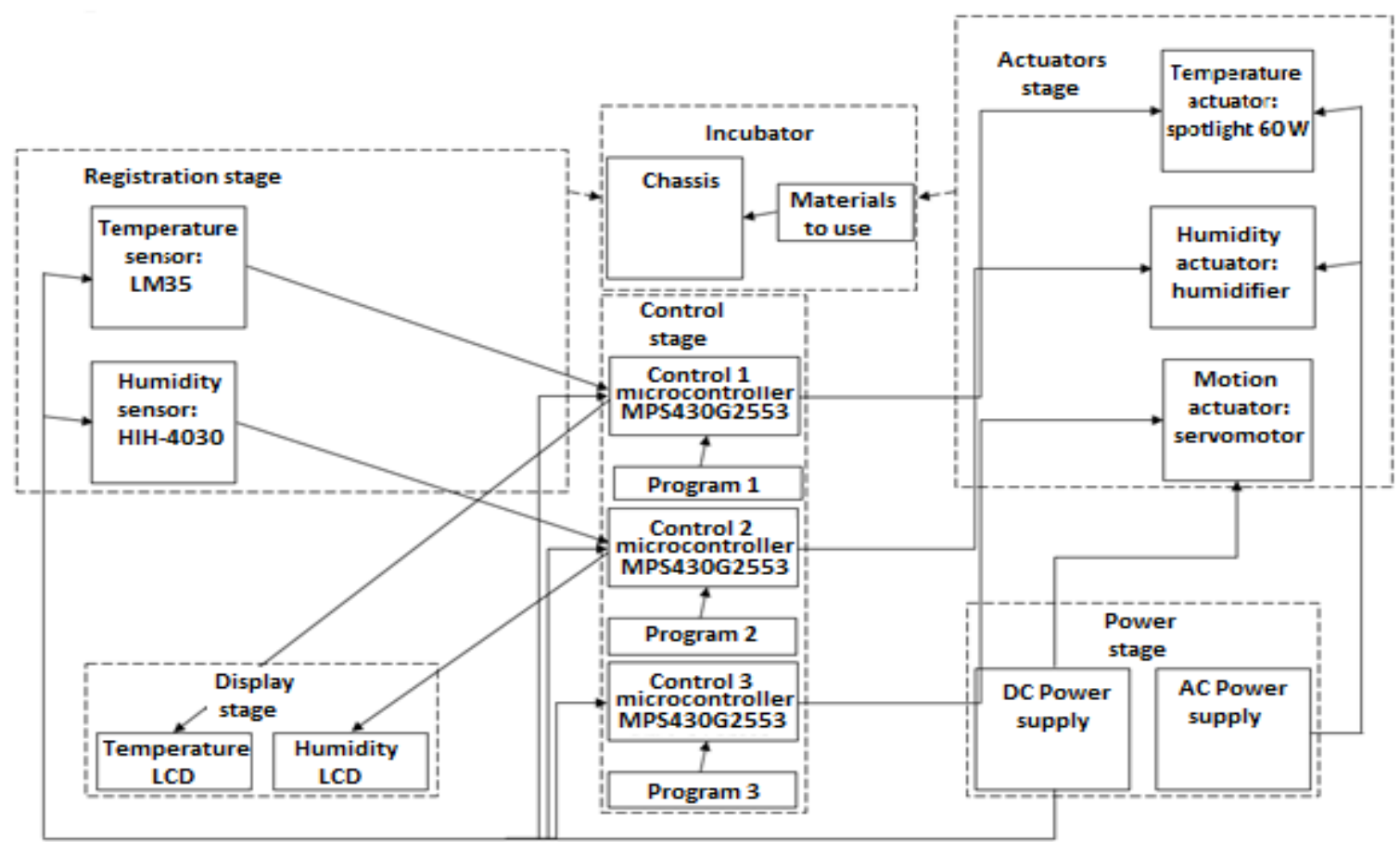

Fig. 1 Incubator prototype block diagram

For the construction of the chassis, the synthetic rubber of the tires was used since it meets the requirements of being thermal, electrical and waterproofing insulator, in addition to not deforming with heat unless it is subjected to temperatures higher than $100^{\circ} \mathrm{C}$ [6]. It also has the characteristic of being an elastic material, it retracts quickly and due to the circular shape of the tire it maintains a homogenized temperature inside. Because the tire only covers the lateral parts of the incubator chassis, it is necessary that some material covers the lower and upper part of the incubator, this material must be transparent so that the interior of the incubator can be seen, so It was necessary to use acrylic with a thickness that withstands heat so as not to deform, as shown in Fig. 2.

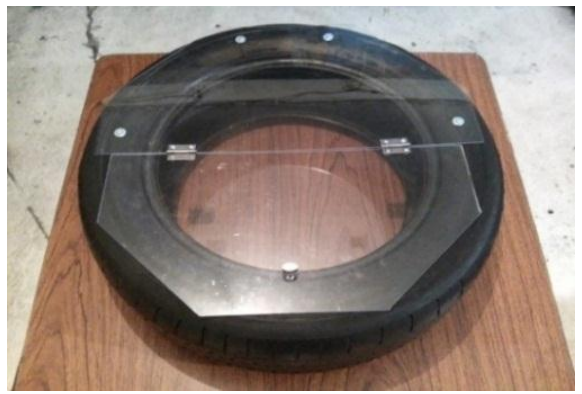

Fig. 2 Incubator chassis

The incubator was designed for a capacity of $8 \mathrm{eggs}$, which are placed in a tray and this is where the temperature and humidity sensors will be placed, as shown in Fig. 3.

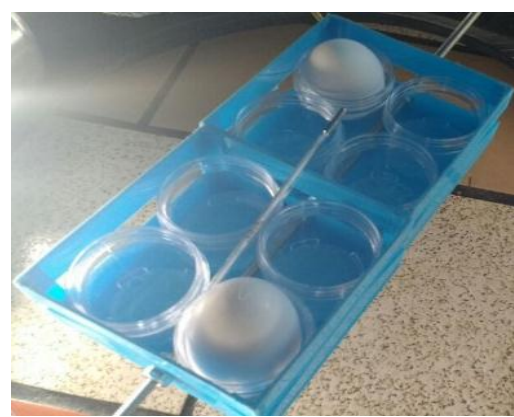

Fig. 3 Tray to place 8 eggs 


\section{International Journal of Advanced Research in Computer and Communication Engineering}

Vol. 9, Issue 10, October 2020

\section{DOI 10.17148/IJARCCE.2020.91016}

Within the registration stage, the temperature and humidity sensor is contemplated. For the temperature measurement, the LM35Z sensor was used, since it is precision, has a linear output voltage proportional to the temperature in degrees centigrade and does not need an external calibration; it was placed in the center of the egg tray. The HIH-4030 sensor was used for the relative humidity measurement, due to its precision. It presents a semilinear output voltage to humidity in percentage of relative humidity and if an external calibration is required; it was also placed in the middle of the egg tray.

In the actuators stage, two $50 \mathrm{~W}$ infrared bulbs were used to generate heat. The spotlights have a reflector to focus heat in any direction and this type of spotlight is also designed for setting terrariums, that is, they are aimed at caring for living beings. The placement of the bulb and the lamp holder is shown in Fig. 4. In addition to covering the inside of the tire with aluminum foil, a fan was placed to generate an air current and in this way expand the hot air (temperature) homogeneously throughout the tire. At this stage, an ultrasonic humidifier is also used to generate humidity and this was placed at the southern end of the tire, as shown in Fig. 4.

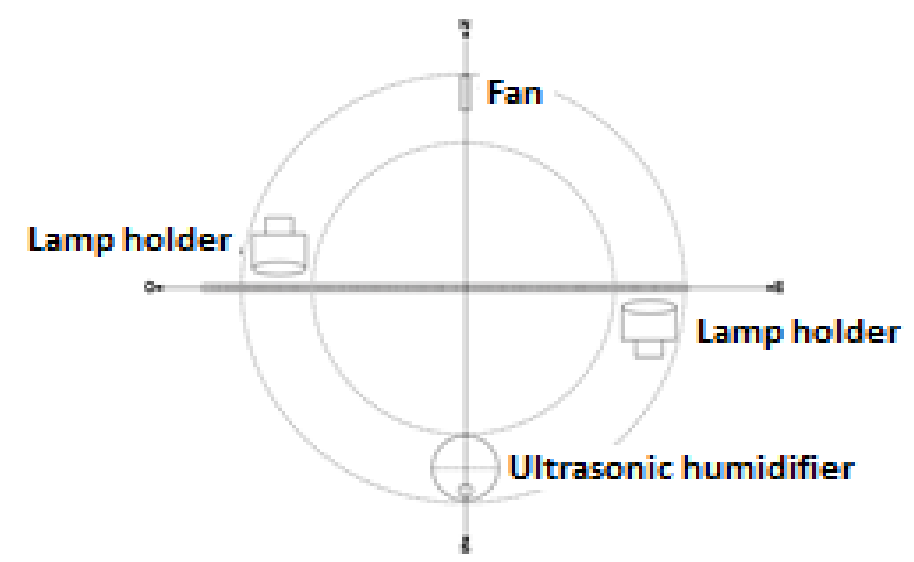

Fig. 4 Position of the lamp holders and the ultrasonic humidifier

The egg weight of the Cobb 500 hen depends on the body weight of the hen, its level of production and the level of nutrition with which the flock is fed. However, the Cobb 500 "Breeder Management Supplement" guide indicates that the hatching eggs must weigh at least $50 \mathrm{~g}$ [2], that is why the motor required to perform the turning must has the capacity to turn the 8 eggs ( $400 \mathrm{~g}$ minimum), the FUTABA S3003 servomotor was used for this, as shown in Fig. 5.

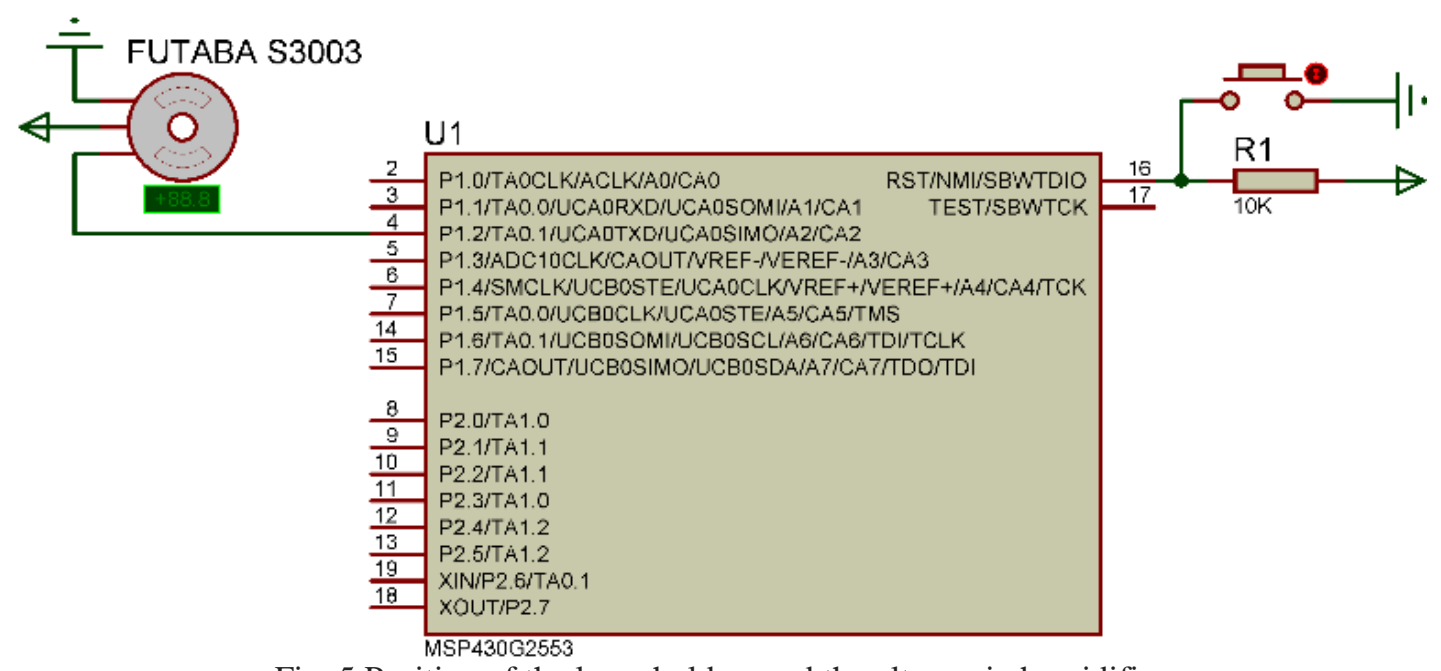

Fig. 5 Position of the lamp holders and the ultrasonic humidifier

The JHD162A liquid crystal display (LCD) was required to display the temperature and relative humidity. The control stage required a microcontroller (MSP430G2553) to perform an ON-OFF control of temperature and humidity. The following Fig. 6 shows the electronic diagram of the temperature and humidity control. 

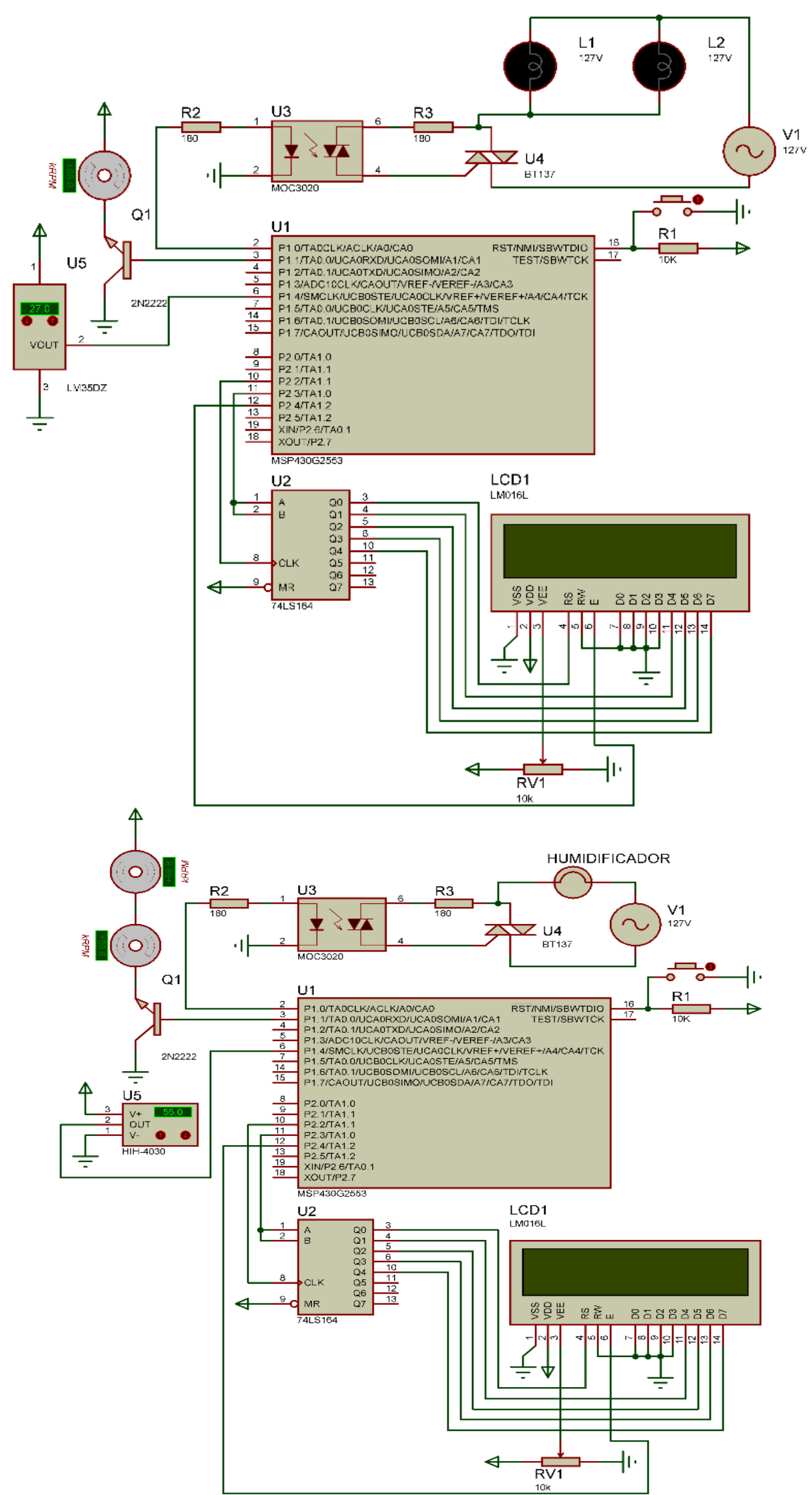

Fig. 6 Electronic diagram of temperature and humidity control 


\section{International Journal of Advanced Research in Computer and Communication Engineering}

Vol. 9, Issue 10, October 2020

\section{DOI 10.17148/IJARCCE.2020.91016}

\section{RESULTS}

In order for the temperature homogenization to be better, two $50 \mathrm{~W}$ lights were used, the stabilization of said required parameter took from 42 to 45 minutes, as shown in Fig. 7.

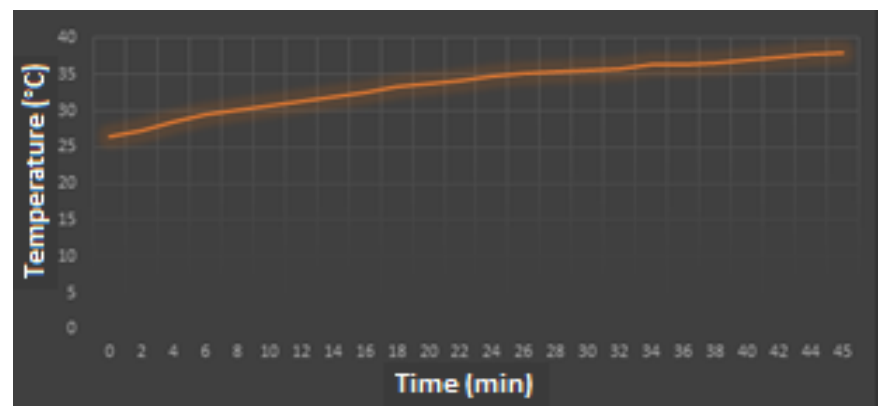

Fig. 7 Graph of temperature increase inside the incubator

Unlike temperature, relative humidity takes less time to reach its required value, the following Fig. 8 shows a measurement that lasted 120 minutes.

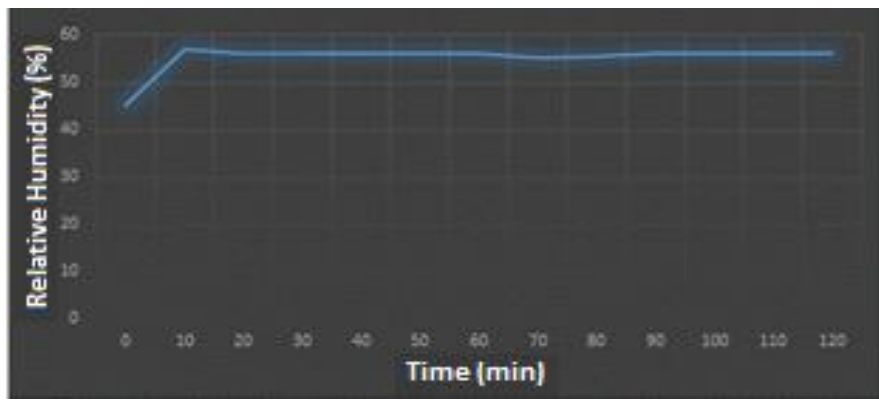

Fig. 8 Graph of the increase and stabilization of relative humidity inside the incubator The final construction of the incubator is shown in Fig. 9.

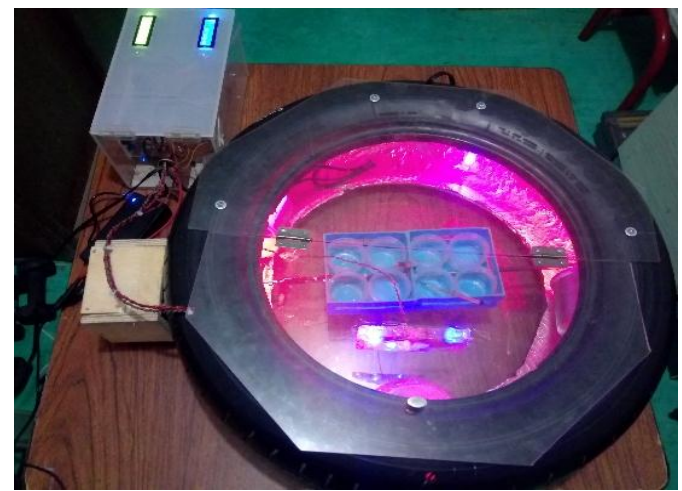

Fig. 9 Construction of the electronic incubator

\section{CONCLUSION}

The construction of the incubator chassis provided the expected results, as it protects the eggs from shock in an aseptic environment, and allows suitable temperature and humidity conditioning for incubation. By placing a $100 \mathrm{~W}$ spotlight in the far north, the temperature took up to 2 hours to reach the required temperature, when the two $50 \mathrm{~W}$ bulbs were placed, the temperature took only 45 minutes, which allows to conclude that the more bulbs are placed in the incubator, the required temperature will be faster to reach, however, the unit price of the prototype will increase. The temperature measured with commercial mercury thermometers in the different individual bases of the egg tray allowed us to know if the temperature was perfectly homogenized, and it was concluded that it was not. However, with the two spotlights placed at the ends of the tray, the aluminum and the fans, it was possible to improve the homogenization of the temperature. 


\section{International Journal of Advanced Research in Computer and Communication Engineering}

Vol. 9, Issue 10, October 2020

DOI 10.17148/IJARCCE.2020.91016

Due to the lack of a hygrometer, the calibration of the relative humidity measurements of the prototype were carried out with the measurements made to the environment by the National Meteorological Service.

Relative humidity has a greater stability than temperature, this is due to the fans placed in the upper cover that are close to the humidifier and, therefore, distribute the steam throughout the incubator. Also, thanks to the fans, it takes much less time for humidity to reach the required value.

The construction of the information display and electronic control system allows to observe the value of temperature and humidity with one tenth of accuracy. Regarding the electronic control of the turning, the motor adequately supported the weight of the $8 \mathrm{eggs}$, remembering that the eggs must be turned during the incubation process. This prevents the embryo from sticking to the shell membranes, particularly in the first week of incubation and helps the development of the embryo's membranes.

It is important to mention that this prototype is susceptible to improvement, since THP thermostats are currently used, these devices are intelligent and have Wi-Fi communication that includes an app to program and control the temperature and humidity of the incubator

\section{ACKNOWLEDGMENT}

Very especially to the students: Miguel Ángel Jasso and Saúl Robles for their contribution in the realization of the prototype.

\section{REFERENCES}

[1]. L. A. Vaca, Poultry Production. Ed. UVED, 2009.

[2]. B. O. Bonilla and S. O. Díaz, Basic elements for handling farm animals, Ed. EUED, 1990.

[3]. E. A. Angulo, Avian Physiology, Ed. University of Lleida, 2009.

[4]. 2020 Cobb website. [Online]. Available: http://www.cobb-vantress.com/languages/guidefiles/7df1f9a1-c867-4290-bd36-3aeb0ba48d25_es.html

[5]. Cobb, Incubator Management Guide, Ed. Trillas, 2013.

[6]. F. W. Billmeyer, Polymer Science, Ed. Reverté, 2004.

\section{BIOGRAPHY}

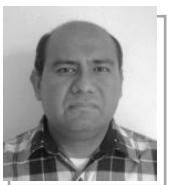

Joel Flores Martínez received his B.Sc. in electronics and communications engineering from ESIME Zacatenco IPN, Mexico, in 1997 and M.Sc. degree in Bioelectronics from CINVESTAV IPN, Mexico in 2000. Currently he is a Professor at the Department of Electronics and Communications engineering in ESIME Zacatenco. His research interests are in acoustics and biomedical engineering.

Gerardo Suárez received his B.Sc. in mechanics engineering from ESIME Zacatenco IPN, Mexico, in 1980. Currently he is a Professor at the Department of Electronics and Communications engineering in ESIME Zacatenco. His research interests are in machine control. 